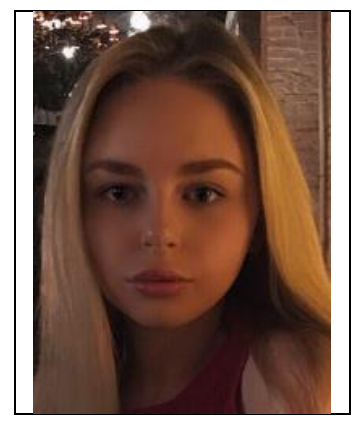

\title{
ОСОБЕННОСТИ МАРКЕТИНГОВОЙ ДЕЯТЕЛЬНОСТИ ПРЕДПРИЯТИЙ СЕЛЬСКОХОЗЯЙСТВЕННОЙ ОТРАСЛИ
}

\author{
А.А. Беляева, студент 2-го курса магистратуры, \\ e-mail: nastyabelyaeva1@yandex.ru, \\ ФГБОУ ВО «Калининградский государственный \\ технический университет»
}

Научная статья посвящена особенностям маркетинговой деятельности предприятий сельскохозяйственной отрасли. Дается характеристика структуры агропромышленного комплекса Российской Федерации и рассматриваются особенности сельского хозяйства как части агропромышленного комплекса экономики. Дается определение агромаркетинга как отдельного направления маркетинга, перечисляются его задачи, особенности, основные проблемы развития агромаркетинга в России. Научная новизна исследования заключается в обобщении особенностей сельскохозяйственного маркетинга, а также в том, что теоретические положения подкрепляются примером анализа элементов маркетинговой деятельности крестьянско-фермерского хозяйства Калининградской области ИП КФХ Тасалиев Д.М. Дается краткая характеристика крестьянско-фермерского хозяйства, делается анализ маркетинговой деятельности методом 4p: продукт-цена-продвижение-месторасположение, подкрепленный табличными и графическими данными. Сделан анализ основных показателей КФХ Тасалиев Д.М. за 2017-2019 гг. По результатам проведенного анализа выявляются преимущества и недостатки маркетинговой деятельности КФХ Тасалиев Д.М., предлагаются пути ее совершенствования.

Ключевые слова: маркетинговая деятельность, сельское хозяйство, агропромылиленный комплекс, агромаркетинг, крестьянско-фермерское хозяйство, молочная продукиия, фермерская продукция

\section{ВВЕДЕНИЕ}

Состояние современной экономики России требует от всех предприятий уделять особое внимание маркетинговой деятельности, ведь конкурентоспособность предприятий зависит не только от того, насколько качественная продукция производится и продается, но и от того, как именно данная продукция продвигается на рынок и доходит до конечного потребителя. Это относится в полной мере и к предприятиям агропромышленного комплекса (далее - АПК). Маркетинг для предприятий АПК позволяет им успешно функционировать в рыночных условиях и соответствовать требованиям, предъявляемым рынком [2, с. 27].

Маркетинг в АПК имеет свои особенности, связанные, прежде всего, с особенностями самой отрасли. Он получил название агромаркетинг, или сельскохозяйственный маркетинг, так как сельское хозяйство занимает большую долю в АПК. Разнообразие ассортимента продукции, форм хозяйствования участников рынка способствуют тому, что к маркетинговой деятельности предприятий АПК предъявляются особые требования [6].

Создание стабильно развивающейся системы управления маркетингом на предприятиях АПК позволит решить как проблемы отдельного предприятия, так и всей системы отечественного агромаркетинга.

\section{ОБЪЕКТ ИССЛЕДОВАНИЯ}

Объектом исследования выступили составляющие комплекса маркетинга сельскохозяйственных предприятий. 


\section{ЦЕЛЬ И ЗАДАЧИ ИССЛЕДОВАНИЯ}

Целью исследования является анализ особенностей маркетинговой деятельности предприятий сельскохозяйственной отрасли.

Задачи исследования: кетинга);

- определение сущности и особенностей сельскохозяйственного маркетинга (агромар-

- проведение практического исследования составляющих комплекса маркетинга крестьянско-фермерского хозяйства Калининградской области ИП КФХ Тасалиев Д.М.;

- выявление достоинств и недостатков маркетинговой деятельности КФХ Тасалиев Д.М., разработка путей ее совершенствования.

\section{МЕТОДЫ ИССЛЕДОВАНИЯ}

Методы исследования: теоретические (анализ, синтез, обобщение, сравнение), эмпирические (статистический, метод анализа маркетинга 4p).

\section{РЕЗУЛЬТАТЫ ИССЛЕДОВАНИЯ}

Сельское хозяйство занимает важнейшую часть экономики любой страны, ведь оно обеспечивает население продуктами растениеводства и животноводства. Сельское хозяйство составляет основу АПК России, первостепенная задача сельского хозяйства - производство продуктов питания для населения и сырья для целого ряда отраслей экономики [4, с. 77]. На рис. 1 изображена структура АПК России: можно убедиться, что сельское хозяйство является как бы связующим звеном, объединяющим и другие сферы, входящие в АПК: ресурсов, сервиса и маркетинга.

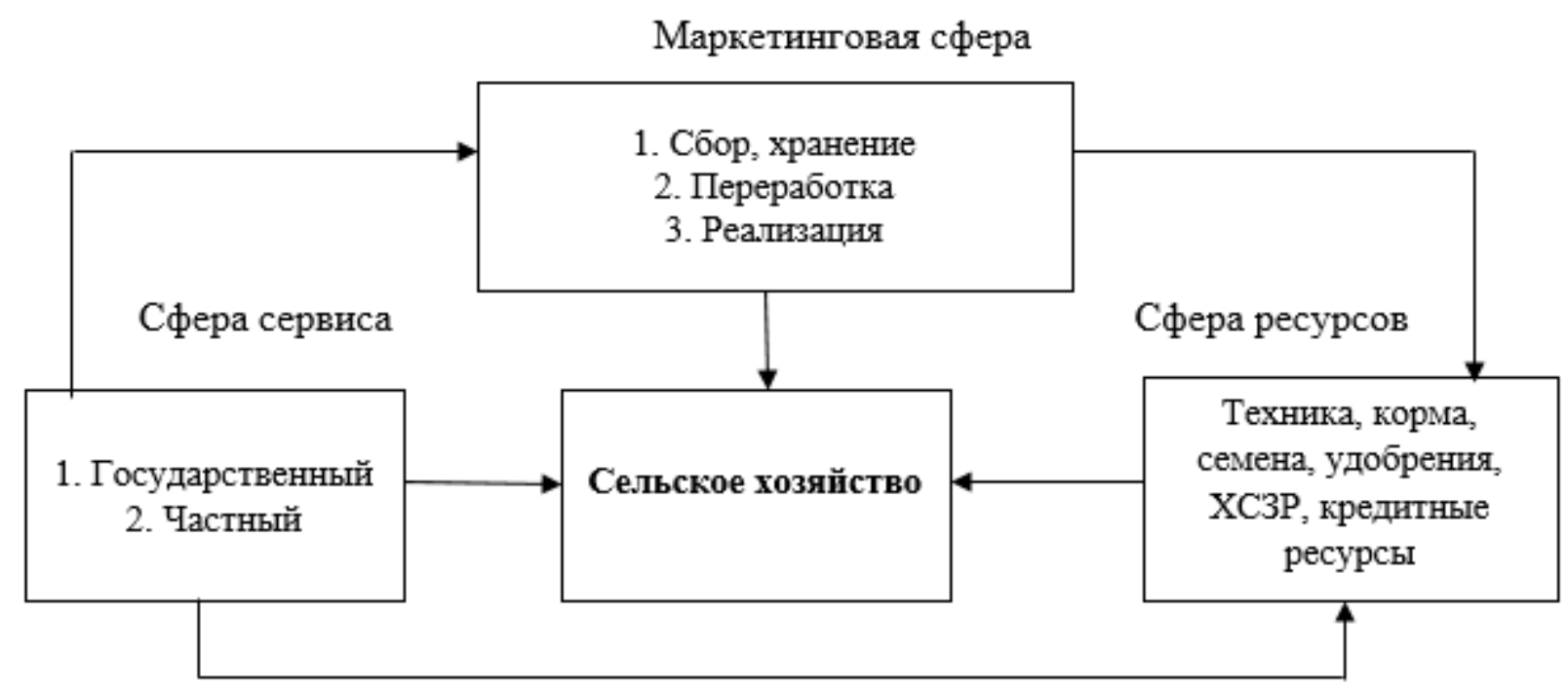

Рисунок 1 - Структура агропромышленного комплекса Российской Федерации

Агропромышленный маркетинг можно определить, как направление маркетинга, включающее изучение, прогнозирование и осуществление предпринимательской деятельности хозяйствующих субъектов рынка в области производства, переработки, хранения, транспортировки и реализации сельскохозяйственной продукции с целью получения высоких результатов рыночной деятельности [3, с. 48]. Агропромышленный маркетинг способствует более обоснованному выбору товара; установлению качественных параметров производства; обоснованию сроков и объема производства сельскохозяйственной продукции; разработке бизнес-плана внедрения новых технологий или нового продукта и т.д.

На развитие агромаркетинга влияют особенности и тенденции развития сельского хозяйства: сезонность, различие в плодородии земель, связь производственно-экономических процессов с природно-биологическими, различия в погодных условиях в разных частях 
страны [4, с. 79-81]. Все указанные выше особенности необходимо учитывать при организации маркетинговой деятельности конкретного предприятия, осуществляющего деятельность в сельском хозяйстве.

Система сельскохозяйственного маркетинга включает различные потоки продукции (каналы маркетинга), множество посредников (предприятия в системе маркетинга) и разнообразные формы деловой активности (функции маркетинга) [5, с. 169] (рис. 2).

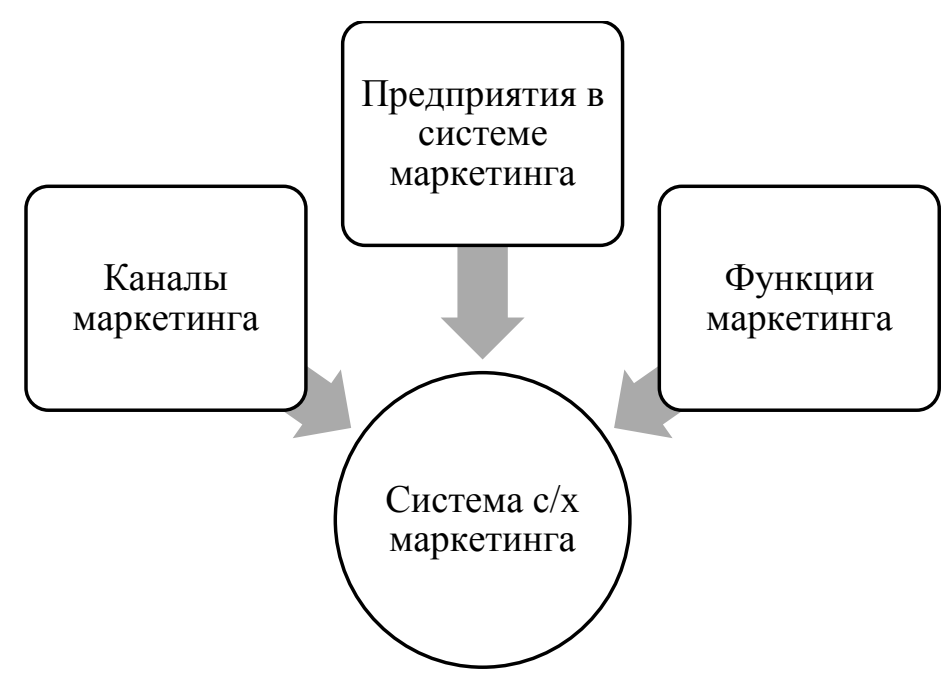

Рисунок 2 - Система маркетинга в сельском хозяйстве

Следует отметить, что на сегодняшний день, несмотря на то, что АПК в России - одна из основных отраслей экономики, сфера агромаркетинга остается недостаточно развитой. На его развитие негативно сказываются отсутствие должного количества специалистов в этой области, неразвитость маркетинговой информационной среды, невысокий уровень знаний руководителей предприятий о продвижении своей продукции, отсутствие единого информационного пространства и т.д. [2, с. 34].

Объектом исследования выступило крестьянско-фермерское хозяйство (ИП КФХ) Тасалиев Джаттай Магомедович. На сегодняшний день на двух фермах Д.М. Тасалиева в общей сложности 580 голов крупного рогатого скота и парнокопытных. По структуре большую часть поголовья составляют коровы (66 \%), козы занимают 22, а овцы - 12 \%. При этом фермер планирует и далее расширяться. Особенностью организации фермерского хозяйства ИП Тасалиева Д.М. является практически 100\%-ная автоматизация всего процесса производства молока и молокопродуктов.

Анализ маркетинговой деятельности предприятия может быть проведен методом 4p [1]:

1. Продукт (Product). Основная деятельность предприятия ИП КФХ Тасалиев Д.М. связана с производством продуктов питания, а именно молочной продукции. Ниже в табл. 1 представлены данные по товарообороту исследуемого предприятия.

Таблица 1 - Товарооборот ИП КФХ Тасалиев Д.М. в 2017-2019 гг., тыс. руб.

\begin{tabular}{|l|c|c|c|c|l|c|c|}
\hline \multirow{2}{*}{ Наименование показателя } & \multicolumn{3}{c|}{ Годы } & \multicolumn{2}{c|}{$\begin{array}{c}\text { Абсолютное } \\
\text { изменение }\end{array}$} & \multicolumn{2}{c|}{$\begin{array}{c}\text { Относительное } \\
\text { изменение, \% }\end{array}$} \\
\cline { 2 - 10 } & 2017 & 2018 & 2019 & 2018 & 2019 & 2018 & 2019 \\
\hline 1 & 2 & 3 & 4 & 5 & 6 & 7 & 8 \\
\hline Молоко коровье & 13114 & 17528 & 14134 & 4414 & -3394 & 33,66 & $-19,36$ \\
\hline Молоко козье & 2568 & 3998 & 3115 & 1430 & -883 & 55,69 & $-22,09$ \\
\hline Творог & 1809 & 2401 & 2011 & 592 & -390 & 32,73 & $-16,24$ \\
\hline Сметана & 596 & 1895 & 963 & 1299 & -932 & 217,95 & $-49,18$ \\
\hline Кефир & 1478 & 1533 & 1033 & 55 & -500 & 3,72 & $-32,62$ \\
\hline
\end{tabular}


Окончание табл. 1

\begin{tabular}{|l|l|l|l|l|l|l|l|}
\hline \multicolumn{1}{|c|}{1} & \multicolumn{1}{c|}{2} & \multicolumn{1}{c|}{3} & \multicolumn{1}{c|}{4} & \multicolumn{1}{c|}{5} & \multicolumn{1}{c|}{7} & \multicolumn{1}{c|}{8} \\
\hline Айран & 501 & 1092 & 1105 & 591 & 13 & 117,96 & 1,19 \\
\hline Простокваша & 399 & 680 & 358 & 281 & -322 & 70,43 & $-47,35$ \\
\hline Ряженка & 494 & 815 & 419 & 321 & -396 & 64,98 & $-48,59$ \\
\hline Сливки & 653 & 498 & 347 & -155 & -151 & $-23,74$ & $-30,32$ \\
\hline Масло топленое коровье & 479 & 652 & 337 & 173 & -315 & 36,12 & $-48,31$ \\
\hline Сыр козий мягкий & 195 & 487 & 327 & 292 & -160 & 149,74 & $-32,85$ \\
\hline Сыр козий полутвердый & 350 & 699 & 736 & 349 & 37 & 99,71 & 5,29 \\
\hline Сыр овечий полутвердый & - & - & 269 & - & 269 & - & - \\
\hline Сыр мягкий адыгейский & 288 & 594 & 312 & 306 & -282 & 106,25 & $-47,47$ \\
\hline Сыр эксклюзивный фермерский & 427 & 648 & 314 & 221 & -334 & 51,76 & $-51,54$ \\
\hline Итого & 23351 & 33520 & 25780 & 10169 & -7740 & 43,55 & $-23,09$ \\
\hline
\end{tabular}

Как видно из данных табл. 1, основная доля товарооборота приходится на коровье молоко (в 2019 г. - 14134 тыс. руб., что составляет 55 \% от товарооборота), чуть меньше составляет козье молоко - $12 \% ; 8 \%$ - творог. Остальные позиции в сумме составляют $25 \%$ товарооборота (рис. 3).

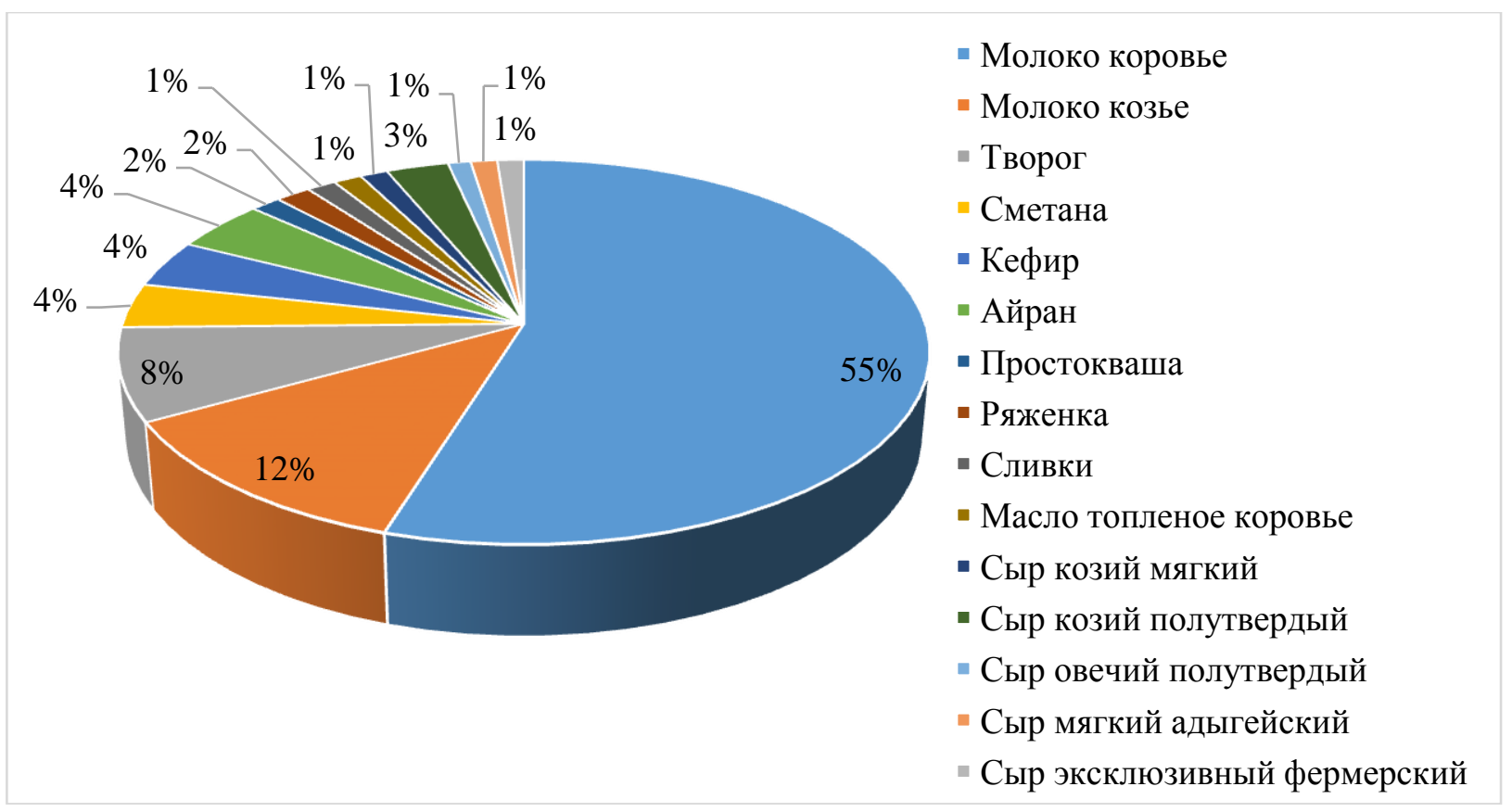

Рисунок 3 - Структура товарооборота ИП КФХ Тасалиев Д.М. в 2019 г.

Динамика товарооборота по отдельным позициям: в 2019 г. почти все позиции снизились в продажах: товарооборот по коровьему молоку снизился на 19,36, козьему молоку - на 22,09 \%. Снижение товарооборота почти вполовину показали сметана, простокваша, ряженка, масло топленое, сыр мягкий адыгейский, сыр эксклюзивный фермерский. Положительная динамика наблюдается по таким товарам, как айран $(1,19 \%)$, козий полутвердый сыр $(5,29 \%)$, впервые появляется овечий сыр - его продажи составили 269 тыс. руб.

2. Цена (Рrice). От выбора политики ценообразования зависит почти вся деятельность крестьянского фермерского хозяйства. Необходимо установить такие цены, чтобы продажи продукции по каждой позиции стали рентабельными, т. е. давали доход и прибыль.

ИП КФХ Тасалиев Д.М. выбрал затратный метод установления цен на свою продук- 
цию: от себестоимости товара делается наценка 25-30 \%. В своем магазине или в цеху товар продается по этой цене, а торговые сети делают свою торговую наценку $25 \%$. Если магазин реализует продукцию КФХ Тасалиев Д.М. с наценкой не более 20 \%, то фермер забирает непроданную продукцию. Таким образом, цена на продукцию КФХ Тасалиев Д.М. устанавливается следующим образом (рис. 4).

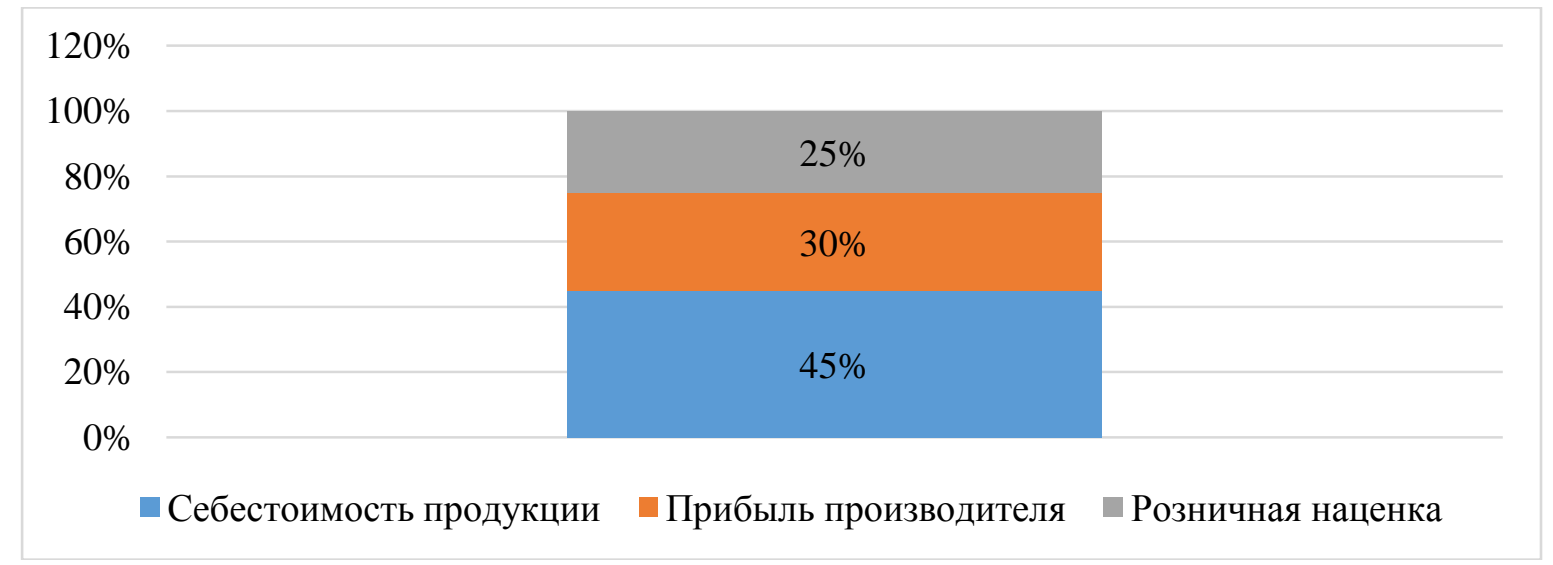

Рисунок 4 - Ценообразование продукции ИП КФХ Тасалиев Д.М.

3. Продвижение (Promotion). В основном глава КФХ использует прямой сбыт. 80 \% продаж осуществляется через торговую сеть «Виктория», 20 - через другие и собственный магазины. Сам фермер не использует активную маркетинговую политику продвижения, на рекламу в крестьянско-фермерском хозяйстве не выделяется денег. Следует отметить, что информацию о товарах КФХ Тасалиев Д.М. узнать, а также приобрести товары можно в Интернет-магазинах, однако это магазины-перекупщики (те, кто покупает продукцию в цеху, а продает уже с наценкой).

4. Месторасположение (Place). Фермы ИП Тасалиева Д.М. расположены в Гвардейском и Зеленоградском районах. Продукция же продается в магазинах торговой сети «Виктория» по всему Калининграду, в магазинах торговой сети «Натурово», а также в магазинах области. Таким образом, можно сделать вывод о хорошем географическом покрытии Калининградской области продукцией ИП КФХ Тасалиев Д.М.

Подведем итог проведенному анализу маркетинговой деятельности ИП КФХ Тасалиев Д.М.

Преимуществом продукции и деятельности ИП КФХ Тасалиев Д.М. является 100\%-ная натуральность продукции, высокая степень автоматизации производства. Фермер имеет большие планы на развитие фермерского хозяйства, в том числе расширение ассортимента продукции за счет продукции из овечьего молока. Однако при отсутствии грамотного продвижения и расширения географического покрытия продукцией города и региона товарооборот может остаться прежним или даже уменьшиться. Поэтому крестьянскому фермерскому хозяйству необходимо наладить маркетинговую деятельность, прежде всего, с целью повышения узнаваемости продукции фермера на торговых прилавках.

Первоначальные действия:

- составить план маркетинговых мероприятий на 2020-2021 гг. и распланировать бюджет маркетинга;

- проанализировать географический охват рынка продукцией предприятия и определить потенциальные рынки сбыта;

- организовать мероприятия по маркетинговому продвижению всей продукции и отдельных категорий товаров;

- провести ряд мероприятий по узнаваемости продукции и производителя;

- организовать рекламу продукции в торговых сетях и розничных магазинах Калининградской области. 


\title{
ЗАКЛЮЧЕНИЕ
}

Таким образом, в данной статье были рассмотрены теоретические положения организации маркетинговой деятельности сельскохозяйственных предприятий, а также приведен анализ маркетинговой деятельности конкретного сельскохозяйственного предприятия.

Научная новизна исследования заключается в обобщении теоретических составляющих сельскохозяйственного маркетинга, а также поэтапном анализе маркетинговой деятельности крестьянско-фермерского хозяйства ИП КФХ Тасалиев Д.М. на основе метода 4p, в результате чего выявлены преимущества и недостатки маркетинговой деятельности и определены пути ее совершенствования.

Теоретическая значимость исследования заключается в том, что на основе данных о его сущности, задачах, функциях построена схема системы маркетинга в сельском хозяйстве.

Практическая значимость исследования заключается в возможности использования результатов анализа маркетинговой деятельности по методу $4 \mathrm{p}$ в дальнейшем планировании маркетинговой деятельности ИП КФХ Тасалиев Д.М.

\section{СПИСОК ЛИТЕРАТУРЫ}

1. Бойков, В. Маркетинговая политика / В. Бойков // Управление корпоративными финансами. - 2014. - № 3. - С. 45-49.

2. Камилов, М.К. Маркетинг на предприятиях АПК и проблемы его развития / М.К. Камилов, П.Д. Камилова, 3.М. Камилова // Региональные проблемы преобразования экономики. - 2015. - № 6. - С. 27-35.

3. Маркетинг в отраслях и сферах деятельности: учебное пособие / сост. Е.А. Якимова. - Красноярск: Сиб. федер. ун-т, 2012. - 211 с.

4. Морозов, Ю.В. Маркетинг в отраслях и сферах деятельности: учебник / Ю.В. Морозов, В.Т. Гришина. - Москва: Дашков и К, 2012. - 448 с.

5. Шамис, В.А. Маркетинг в отраслях и сферах деятельности: учебное пособие / В.А. Шамис. - Омск: Издатель ИП Погорелова Е.В., 2010. - 209 с.

6. Карташов, Ф.Н. Развитие маркетинговой деятельности на предприятиях сельского хозяйства / Ф.Н. Карташов, О.И. Егорцев. [Электронный ресурс]. - URL: http://sisupr.mrsu.ru/2010-4-APK/PDF/Egortseva.pdf (дата обращения 01.05.2020).

\section{FEATURES OF MARKETING ACTIVITIES OF AGRICULTURAL ENTERPRISES}

\author{
A.A. Belyaeva, master's student, \\ e-mail: nastyabelyaeva1@yandex.ru, \\ Kaliningrad State Technical University
}

The scientific article is devoted to the peculiarities of marketing activities of agricultural enterprises. The article describes the structure of the agro-industrial complex of the Russian Federation and considers the features of agriculture as part of the agro-industrial complex of the economy. The definition of agromarketing as a separate marketing direction is given, its tasks, features, and main problems of agromarketing development in Russia are listed. The theoretical provisions are supported by an example of the analysis of elements of marketing activities of a peasant farm in the Kaliningrad region. Tasaliev D. M. gives a brief description of the peasant farm, the analysis of marketing activities using the 4P method: product-price-promotion-place. The analysis is supported by tabular and graphical data, and the analysis of the main indicators of D. M. Tasaliev for 20172019 is made. Based on the analysis, the advantages and disadvantages of marketing activities are identified Tasaliev D. M., and ways to improve it are proposed.

Key words: marketing activities, agriculture, agro-industrial complex, agromarketing, peasant farming, dairy products, farm products 